\title{
Mutiny over Bounty?
}

\author{
T HUTCHISON, C J ROLLES
}

\begin{abstract}
Bounty Services Ltd advertise commercial products on postnatal wards of hospitals throughout Britain by means of free gifts. Since the "Bounty lady" is apparently well known to nursing staff but may have gone unnoticed by paediatricians and obstetricians an investigation was conducted of the quality of the gifts and the nature of the company.

With two exceptions the samples and promotional leaflets were sound, and mothers apparently enjoyed receiving them. Educational pamphlets distributed with the gifts were excellent, and cine films shown to the mothers were of good quality and informative about basic parental skills. Bounty, however, operates by exerting commercial pressure on new mothers at a time when they are most vulnerable and distributes materials among them without consultation with medical staff. Most of the mothers questioned assumed that the service was being provided by the NHS.

The Bounty service may or may not be perceived as a satisfactory operation but details should be known to paediatricians and obstetricians; any action to be taken might be decided locally after discussion in individual hospitals or districts.
\end{abstract}

\section{Introduction}

Talk of "privatising" parts of the National Health Service such as cleaning and catering raises storms of protest. Unknown to most of us, however, a small part of postnatal education has long been the territory of one entrepreneurial commercial organisation.

We refer to Bounty Services Ltd, who operate in our local maternity hospital (5000 deliveries a year) as in others throughout Britain. The "Bounty lady," a housewife with two children, spends four hours each week distributing her free bags of gifts on our postnatal wards. She arrives and identifies herself to the nursing staff by her badge, her clipboard, and her trolley of bags. She then ascertains which new mothers are well enough to be visited. To each a bag is given; from each a name and address is taken; and for each a commission is received.

This routine, by someone who has become "almost a member of hospital staff," has continued for years virtually unnoticed by obstetric and paediatric medical staff. Having spotted our local

\footnotetext{
Department of Paediatrics, Princess Anne Maternity Hospital, Southampton

T HUTCHISON, MRCP, paediatric registrar

C J ROLLES, FRCP, consultant paediatrician

Correspondence to: Dr C J Rolles.
}

Bounty lady at work-and realising that we knew very little about this "service" to mothers going on under our noses-we decided to look into the matter. During our investigations we came to opposing conclusions about the Bounty service, one of us being in favour and the other not. In an effort to make positive use of our disagreement we present here some factual information along with our differing opinions in the hope that they will encourage constructive discussion.

\section{Who is Bounty?}

The founder and chairman of Bounty Services Ltd was unhappy with the unsolicited mailings and samples that his wife received after the announcement of his son's birth in the press in 1957. As a result he set about a personal campaign, which gradually became a full time job and a profitable "middle man" service. Bounty does not manufacture any product. Instead, it provides an advertising service to which commercial clients can send samples, vouchers, and other promotional materials. Bounty packages these, along with educational pamphlets such as the Bounty book, in the Bounty bag, which is then distributed free. Bounty is paid by its clients.

In 1981 Bounty expected to reach $85 \%$ of new mothers-625000 in all. In a card which it mails to clients it proudly quotes from a market survey of publications for new mothers (carried out in the summer of 1979 by Research Surveys of Great Britain Ltd, whose detailed results are apparently confidential) to show that the Bounty book has the biggest circulation and readership and is regarded as "the most helpful" by the highest percentage of mothers. Bounty boasts: "Such success is hardly surprising. The Bounty Baby Book is the most cost effective way of advertising to the mother and baby market with no wastage and total accuracy. This is achieved by its unique method of distribution-reaching new mothers shortly after the birth, when they're at their most receptive."

\section{What else does Bounty provide?}

Bounty has stationed a cine film loop projector in the hospital. The Bounty lady moves this around the different wards and is commissioned according to the number of mothers who sign up as having watched the films. There are five titles: Bottle Feeding, Breast Feeding, Weaning, Changing and Bathing, and At Home with Baby. Each lasts roughly 13 minutes and has two and a half minutes of advertisements in the middle. These promote bottles, nappies, baby wipes, and baby foods.

Bounty has provided sponsorship money. An educational pamphlet, "How to survive the first week of breast feeding," printed by the Health Education Council, was the winner of a national competition organised by the Royal College of Midwives and sponsored by Bounty.

\section{What do the bags contain?}

We have examined bags at intervals over the past three years. First and second time mothers receive bags of slightly differing contents. Also the contents of both bags alter from month to 
month without any consultation with the hospital. In November 1983 the primipara bag contained the following three types of material:

(1) Product samples-Disposable nappies (one box); sanitary towels (one box); baby cleansing wipes (one jar); dried beef broth weaning food (one packet); liquid baby bath soap (one bottle); disinfectant cream (one sachet); baby lotion (one bottle).

(2) Promotional leaflets, coupons, and catalogues-Soap; rusks; baby bottles and steriliser; branded baby food; knitting patterns; mail order film processing; mail order catalogues for toys, children's clothes, general merchandise for children.

(3) Educational-"Bounty baby book"; "From milk to mixed diets" (guide to weaning); "For the attention of fathers" (contraceptive guide).

The multipara bag omitted the sanitary towels and baby lotion but included advertisements for toothpaste and children's books, as well as a copy of the periodical Children's Progress.

\section{Evaluation}

In March 1983 we reviewed the contents of the bag with the hospital dietitian and pharmacist. We found the products sound, with two notable exceptions. Both were absent from bags examined in November, and we hope that these two deletions will be permanent.

The first was a leaflet and small bottled sample promoting a well known brand of sweetened fruit juice. These strongly suggested that breast and bottle fed babies needed vitamin C supplements to remain healthy. The back of the bottle has a daily dosage schedule- "up to one month one teaspoonful." This is nutritional nonsense.

The second was a leaflet advertising a French mineral water for the reconstitution of infant feeds. It is "the baby water you don't have to boil." We thought this suggestion absurd, not to mention expensive. It contradicts the established recommendation in Britain that all water for infant feeds should be boiled. Finally, though this product is almost mineral free, a mother might be misled into using one of the several mineral waters with a dangerously high sodium content. Vichy Saint-Yorre, for example, has a sodium content of some $70 \mathrm{mmol}(\mathrm{mEq}) / 1$. (Laboratoire National du Ministère de la Santé Publique France, 18 September 1973.)

The educational pamphlets all appeared to be excellent, and we found the films to be well made and informative about the basic parental skills. It was certainly our impression that mothers enjoyed the films as well as the free bag of "goodies." One mother described receiving her bag as being "like Christmas."

\section{Arguments for and against the service}

\section{FOR BOUNTY}

On the credit side:

(1) Bounty is an established part of postpartum ritual, like cards, flowers, and medical examinations.

(2) It has been going for many years and we have no knowledge of complaints from mothers or of harm done to babies.
(3) The products are almost all of established quality and utility.

(4) It fulfils a need for educational materials at a time when resources are scarce.

(5) These materials have been expanded and updated.

(6) The bag contains several pounds' worth of vouchers.

(7) The NHS would never have initiated a service like this, and nor could the NHS match Bounty's efficiency and vigour if "nationalisation" took place.

\section{AGAINST BOUNTY}

On the debit side:

(1) The Bounty lady is not medically trained, yet has more access than a social worker to individual wards and cubicles for purely commercial interests.

(2) The hospital has no control over the contents of the bag, and we have been unable to find more than a minority of doctors who knew any details of the organisation or of the contents of the bag.

(3) Bounty states in small print at the top of the bag that no recommendation by the health authority is implied. Most of the mothers whom we spoke to, however, did not understand Bounty and assumed that the bags came from the NHS. NHS endorsement is implicit in the way Bounty works with such ease within the hospital.

(4) Mothers in the puerperium are susceptible to commercial pressure, and this is recognised and exploited by Bounty.

\section{Options for further action}

Any action taken in respect of Bounty must depend on how the system is perceived. For example, it might be argued that Bounty has a symbiotic relationship with the postnatal wards, is an evolving example of benevolent free enterprise, and should not only be left alone but welcomed; or, alternatively, that the system is satisfactory but should be subject to stricter oversight by, for example, an independent committee set up by the British Paediatric Association.

Some hospitals might consider that they could run an equivalent service themselves. They could cut out the middle man by dealing directly with the companies for free samples. A bag could be made up, the contents of which could be tailored to the particular needs of a hospital population, and the profits go to the NHS. Many more of the Health Education Council's excellent publications could be included in the bag instead of gathering dust in corners of ward sitting rooms.

Conversely, the entire Bounty system may be seen as undesirable exploitation of a vulnerable population in which the NHS should have no part.

\section{Comment}

We disagree in our conclusions about the Bounty operation. We do, however, agree that details of so extensive a service should be known to paediatricians and obstetricians as well as nursing staff. Discussion is always healthy and there is no reason why any individual hospital or district should not hold its own discussions and come to a local decision.

(Accepted 9 March 1984) 